\title{
Engaging Distance Learners in Cooperative Extension ${ }^{1}$
}

\author{
Austen Moore and Amy Harder ${ }^{2}$
}

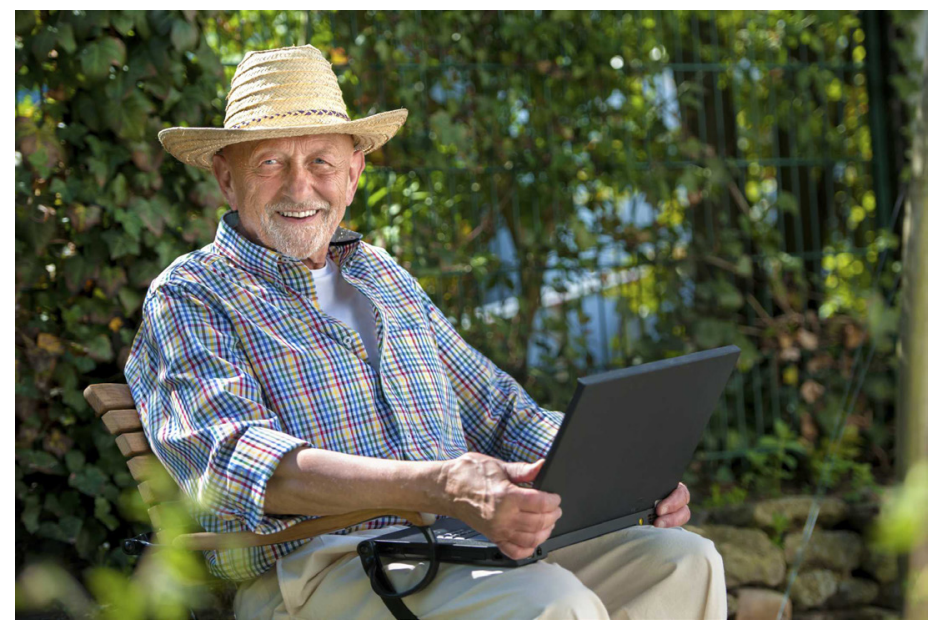

\section{Introduction}

Distance education has been used as a teaching method for many years. Traditional education serves local people and occurs mainly in the classroom. Distance education allows organizations to reach broader audiences, reduce costs per learner, and better serve communities (Newman, 2003).

Early correspondence courses led to the use of television and video as teaching methods (Newman, 2003). More recently, technologies like the Internet have changed distance education even more. Many different types of educators now teach learners at a distance. Cooperative Extension is using distance education more often to teach programs. For example, the eXtension website (www. extension.org) provides information to the public based on research conducted at local universities (Cooperative Extension System, n.d.). County and state Extension faculty also use distance education methods (online resources, mail or electronic newsletters, social media) to teach and inform clientele in their communities.

Distance education is popular and has many benefits. However, teachers are challenged to engage learners in their programs. Interaction is an important part of successful education (Hillman, Willis, \& Gunawardena, 1994). The format of distance education can make this difficult. Instructors must plan and make special efforts to interact with and engage learners. This article discusses how to incorporate the best practices for engaging learners in distance education programs. It focuses most closely on online distance education, an increasingly popular format.

\section{Before Building Your Distance Education Program}

There are a few things to consider before you begin to create your distance education program:

\section{Learner Interaction}

Understanding interaction helps instructors engage learners in distance education. Moore (1989) defined three types of interaction. Learner-content interaction is learners interacting with the information being taught. Instructor-learner interaction is instructors explaining the material and motivating learners. Learner-learner interaction is learners communicating together with or without an instructor. A fourth type of interaction, learner-technology interaction, has been added to this model in recent years (Dooley,

1. This document is AEC479 (formerly WC142), one of a series of the Agricultural Education and Communication Department, Florida Cooperative Extension Service, Institute of Food and Agricultural Sciences, University of Florida. Original publication date May 2013. Visit the EDIS website at http:// edis.ifas.ufl.edu.

2. Austen Moore, doctoral student, and Amy Harder, associate professor, Agricultural Education and Communication Department, Florida Cooperative Extension Service, Institute of Food and Agricultural Sciences, University of Florida, Gainesville, 32611.

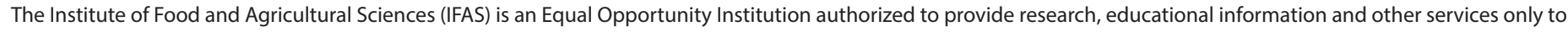

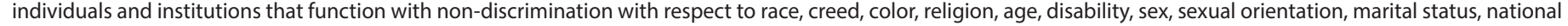


Lindner, Dooley, \& Algeera, 2004). Ways to include the four types of interaction are addressed in this document.

\section{Know Your Audience}

All educators should know their target audience. Try to learn about their backgrounds, learning needs and wants, and experience with the technologies you will use. This is helpful in determining how to design your program (Telg, 1999). A mailed questionnaire is one way to gather this information, or you can contact learners via telephone or email. If you already know who will participate in your program, you can be more specific in the information you gather.

\section{Build a Team}

Distance education usually requires teamwork. Seek people with the skills or experience to help your program (Telg, 1999). Using multiple instructors can expand your clientele base, increase interaction, and add expertise to your team. Your best resources for advice on implementing distance education are your fellow county Extension faculty and regional and state specialists with experience teaching in these formats. A technical support person to assist with any equipment or software problems during the program is helpful, depending upon what type of distance delivery you use. Learners may have problems accessing the material, participating in class activities, and turning in assignments. These problems can be reduced by planning and providing proper technical support.

\section{Online Program Design}

Designing a distance education program is similar to designing a face-to-face program. However, there are extra considerations to make the program engaging.

\section{Select Appropriate Technologies}

Technology is often needed to make distance education effective. There are many options, including mail correspondence, prerecorded video, webinars, individual or conference calls, and videoconferences (Thomas, n.d.). Interactive video sessions that allow groups to remotely participate in Extension programs have been used frequently in recent years. Online systems that allow instructors to post narrated lectures, readings, and assignments are also common. These often include chat rooms and discussion boards that allow learners to interact.

Not all options will be right for your learners. Go back to the information you gathered to see if learners have the skills needed for the methods you hope to use. Do not select technologies your learners don't know (Hillman et al., 1994). This reduces communication, access to the material, motivation, and learning. Instead, choose technologies that learners know for better interaction, communication, and engagement. If you need to use technology that is new to your learners, include extra technical support for them until everyone is comfortable.

Once you choose the best technologies for teaching and learning, look for options that are easy to use. Technologies should be clear, logical, and easy to understand (University of Florida Center for Technology \& Training [CITT], n.d.). Try them yourself before deciding. You may also want to find some training if possible.

Also consider any technological requirements that learners might need. Video- or telephone-based options might require additional hardware that learners may need to buy. Online programs require Internet access, system upgrades, software downloads, or the creation of accounts with login information (Thomas, n.d.). All of these factors should be considered before choosing which technologies to use.

\section{Create a Program Overview Document}

A program overview gives learners the basic information they need. Your document should contain a program description, expectations of participation, learning objectives, a schedule of activities, and the instructor's contact information (University of Florida Center for Distance \& Continuing Education [CDCE], n.d.). You should also include a personal message about yourself to learners (Telg, 1999). This is similar to an introduction on the first day of a program. Distance education documents should also describe how to communicate with the instructor and how soon to expect replies (CDCE, n.d.).

\section{Design Learning Modules}

Distance education programs are often broken down into learning modules or lessons, and groups of teaching materials are centered on one learning objective (University of Florida Center for Online Learning \& Technology [COLT], n.d.). For example, a module that teaches how to use beneficial insects to control pests may contain a narrated lecture or presentation on their use and benefit, a video describing the insect, and a reading on their use with a certain crop. Short-term distance programs may only contain a single module. Longer term programs may contain several modules. Take your learning objectives and build each into a learning module. 
Learning modules can be designed several ways. First, you need a piece that teaches the information you hope to cover. This often includes a narrated lecture, which can either be live or prerecorded (CDCE, n.d.). Less formal presentations, panel discussions, or interactive videos are other ways to teach distance learners.

Modules should also include other activities to engage learners and deepen learning. Lectures or presentations can start with an interest approach (question to the audience, interactive activity, or video clip) meant to create interest in the topic. See Benge and Harder (2008) for more information. Panel discussions or interactive videos might provide some background to the topic relevant to the learners' lives. Using these methods prepares learners for the information presented.

Following the instructional piece of the module, you can use an activity to check for learning and again engage learners. The best way is to ask questions. If the program is happening in real time, then audio/videoconferences, group discussions, or online chats are possible. If the program is not in real time, then telephone conferences, off-site meetings, email, or discussion boards are good options. Other materials (readings or videos) and individual or group assignments should also be included in the module. These can be sent by mail or email. Instructors should also check that links to any online resources still work (CITT, n.d.).

One way to increase learner engagement is called "chunking." Chunking means to divide learning modules into 15-minute pieces. For example, consider showing a video clip or using an interactive activity after a 15-minute presentation. This keeps learners involved and allows time to process new information (Telg, 1999).

Also consider how the information builds on itself when building your modules. Start with a basic overview and make each module more complex as learners develop a foundation. Basically, your modules reflect how the overall program builds knowledge over time.

\section{Program Implementation}

Proper design makes it easier to engage learners when teaching the program. However, there are other things to consider during the teaching period. Following are some issues related to online program implementation.

\section{Orientation Session}

An orientation session allows learners to test and learn the technologies without missing any program material
(Telg, 1999). This is a good opportunity to practice with interactive video and online systems, or to check that phone numbers and email addresses are accurate. The session is helpful even if you choose technologies that learners already know (Hillman et al., 1994). Learners who need more practice with the technology can seek training before beginning the modules. The instructor can also adjust the teaching plan based on learners' skills with the different technologies and methods. For example, if learners have trouble responding to email, it may be necessary to contact individuals by telephone.

\section{Introductions}

Engaging learners requires building connections despite the distance and use of technology. Instructors should introduce themselves to learners (CDCE, n.d.; CITT, n.d.). This introduction should build on the personal message in the program overview document. Include your professional background as well as your interests and other details. In short, let your learners know you as a person to the degree to which you are comfortable. A picture of yourself can further help learners feel more connected to you. Also consider discussing your goals for the program and your own reasons for teaching the material.

Ask learners to introduce themselves and provide some basic guidelines (name, location, or interests). Perhaps ask learners to share an interesting fact or funny story to break the ice. This can be done via audio/videoconferencing, discussion boards, email, or mail correspondence. It is also a good activity for the orientation session.

\section{Building a "Learning Community"}

Learner-learner interaction is part of engaging learners in distance education (Hillman et al., 1994). Teachers should find ways for learners to communicate despite the distances (CDCE, n.d.). Introductions are one method. You can also use team-building activities in the learning modules. These can include group activities, team projects, or the use of discussion boards. Creating familiarity between learners helps them feel part of a "learning community" (Southern Association of Colleges and Schools [SACS], n.d.).

\section{Vary Teaching Tools}

Similar to chunking, using a variety of teaching tools helps keep learners engaged. Rather than alternating between two methods, use the full range of options available to you. Use group activities, discussion boards, online chats, or audio/videoconferences even if you are most comfortable with lectures and presentations. Using a variety of teaching 
methods allows for better feedback, interaction, and learner engagement (Telg, 1999).

\section{Check for Learning}

Frequent checks for learning help keep learners engaged in the lesson. When distance education is conducted live, instructors should ask the audience questions (Telg, 1999). Depending on the method used, learners can respond directly to the instructor in front of the entire group. Otherwise, learners can prepare a written response to be mailed or emailed as appropriate.

\section{Active Program Management}

Distance education instructors must actively manage their programs. This means being accessible to learners on a daily basis. Be prompt and respectful in responding to learners' needs and communications (CDCE, n.d.; COLT, n.d.). Instructors should be willing to answer telephone calls and emails from learners as needed. Instructors using online technologies must also keep up with questions, discussion boards, and submitted assignments (Telg, 1999). Also, technical support must be available (Thomas, n.d.).

\section{Program Assessments and Evaluation}

Assessment and evaluation are important parts of distance education programs. Assessments measure learners' knowledge of the content taught during the course (Telg, 1999). Evaluation measures the program's effectiveness and success (Telg, 1999). Evaluation is also an important way to engage learners. Their thoughts and suggestions can improve the program and benefit their own learning.

\section{Learner Assessments}

Tracking gains in knowledge is part of any educational program. For distance education, you should include a variety of assessments. Traditional exams are possible in some distance formats. Take-home exams, written reports, presentations, and self-evaluation are also common (Telg, 1999). Instructors might also ask questions over the telephone to assess learners' knowledge from a distance.

\section{Formative Evaluation}

Formative evaluation is done during the entire program. Learners provide information and feedback about the delivery and content of the program and the technology used. Changes can then be made in response to learners' needs and requests (Telg, 1999). Instructors can use different methods for gathering formative evaluation data. These include surveys, email, telephone, and discussion boards (Telg, 1999).

\section{Summative Evaluation}

Summative evaluation measures how well the overall program addressed the learning objectives and identifies future improvements (Telg, 1999). Learners describe their attitudes and satisfaction, and make suggestions for the program. Instruments for summative evaluations should ask learners what could have been done differently, what changes could be made, or if they would recommend the course to a peer. Usually this evaluation is done after the program. Results are for the benefit of the instructor or program and do not benefit current learners.

\section{Starting Your Program}

Many Extension professionals have created successful distance education programs. If you feel distance education can help your learners, the best way to create your own program is through experience. Start small, continue to modify and improve it over time, and build your program as you feel comfortable. With flexibility, creativity, and perseverance, you can build a distance education program that engages learners and provides high-quality Extension information to your audience.

\section{References}

Benge, M., \& Harder, A. (2008). Creating interest in learners. AEC393. Gainesville: University of Florida Institute of Food and Agricultural Sciences. Retrieved from http://edis.ifas. ufl.edu/wc074

Cooperative Extension System. (n.d.). eXtension. Retrieved from http://www.extension.org/

Dooley, K., Linder, J., Dooley, L., \& Algeera, M. (2004). Behaviorally anchored competencies: Evaluation tools for training via distance. Human Resource Development International, 7(3): 315-332.

Hillman, D., Willis, D., \& Gunawardena, C. (1994). Learner-interface interaction in distance education: An extension of contemporary models and strategies for practitioners. American Journal of Distance Education, 8(2), 30-42. doi:10.1080/08923649409526853

Moore, M. G. (1989). Three types of interaction. The American Journal of Distance Education 3(2), 1-6. 
Newman, R. D. (2003). Distance education best practices manual. Retrieved from http://www.pdc.edu/wp-content/ uploads/2012/02/Manual_DL-Best-Practices-Manual.pdf

Southern Association of Colleges and Schools. (n.d.). Best practices for electronically offered degree and certificate programs. Retrieved from http://www.sacscoc.org/pdf/ commadap.pdf

Telg, R. (1999). Instructional methods for distance education. AEC345. Gainesville: University of Florida Institute of Food and Agricultural Sciences. Retrieved from http://edis.ifas. ufl.edu/wc026

Thomas, R. (n.d.). Comparison of distance education/ communication technologies. University of Florida Center for Online Learning and Technology. Retrieved from http:// icsde.ifas.ufl.edu/pdf/resources/de_technology_comparison.pdf

University of Florida Center for Instructional Technology and Training (CITT). (n.d.). Retrieved from http://citt.ufl. edu/

University of Florida Distance and Continuing Education (CDCE). (n.d.). DCE's online course preparation guide for instructors. Retrieved from http://www.dce.ufl.edu/ course-production

University of Florida Center for Online Learning and Technology (COLT). (n.d.). Timeline for course development. Retrieved from http://icsde.ifas.ufl.edu/resources-timeline. shtml 